\title{
Breve ensayo sobre el diminutivo en la cocina mexicana*
}

\section{Brief essay about the diminutive in Mexican cuisine}

\author{
SALVADOR MENDIOLA \\ (D) https://orcid.org/0000-0002-6027-0905 \\ Universidad Nacional Autónoma (México) \\ esemendiolaunam@gmail.com
}

\section{Ensayo}

Recepción: 20 de septiembre de 2020

Aceptación: 16 de marzo de 2021

Cómo citar este artículo

Mendiola, S. (2020). Breve ensayo sobre el diminutivo en la cocina mexicana. Sosquua 2(2), pp. 33-39. Recuperado a partir de: http://cipres.sanmateo.edu.co/index.php/sosquua

\footnotetext{
*El autor agradece el trabajo de Gloria Hernández y María Adela Hernández Reyes en la amplia investigación que viene realizando sobre la ("imposible") cocina mexicana.
} 
Todo comenzó hace más de tres (3) décadas, cuando propuse redactar una historia general de la cocina mexicana. Pronto se descubrió que la tarea sería interminable e imposible. Aún no es claro hoy día qué cosa sea (o no) la cocina de México. Por tal motivo, la opción fue estudiar elementos socioculturales y antropológicos que iluminaran la situación de la cocina de los mexicanos. Así se redactó este breve ensayo sobre el papel de los diminutivos dentro de los recetarios, libros de cocina y documentos que hablan de una cocina de México, porque de muchas maneras se ha identificado que estos diminutivos distinguen de modo especial el pensar y actuar de nuestra sociedad.

En realidad, no existe una cocina mexicana única y bien definida; tal concepto o idea solo es un deseo abstracto, irrealizable en concreto: el uno único imposible. Pero esto no quiere decir que la cocina mexicana no tenga una unidad posible y que solo sea un conjunto siempre diverso y disperso de cocinas regionales.

La cocina mexicana es algo más amplio en el espacio terrestre que la geografía nacional actual; en el tiempo es mucho más antigua que la actual República Mexicana. Porque el gran territorio de la cocina mexicana se extiende hasta algo más allá de la mitad de los actuales Estados Unidos de América (EUA), hacia el norte del continente. Además, desciende hasta un poco más allá de Panamá, yendo ahora hacia el sur; asimismo es algo que va desde el océano Atlántico hasta el Pacífico.

En cambio, en el marco del tiempo la cocina mexicana hunde sus raíces en las civilizaciones mesoamericanas, con más de dos (2) mil años de antigüedad; como también incluye de muchas maneras la cocina novohispana. Aunque lo mexicano en esta cocina sea algo con una presencia concreta y real en la historia de no más de tres (3) siglos y medio?.

Por eso la cocina mexicana no es exactamente "nacional" o con una sola identidad; ni siquiera en lo más regional concreto de sus diversas expresiones. Su realidad sociocultural histórica desborda todas las figuras de lo nacional posible. En tal caso, la cocina mexicana es una infinidad de cocinas nacionales con rasgos de familia comunes. Es una cocina concreta para cada región, terruño y momento histórico que pueda ser pensado como mexicano, mejor que como nacional. Aunque lo más objetivo lo concentra en las fronteras del país, le da una historia que comenzó hace dos (2) siglos; además implica pensarse de verdad hace poco más de medio siglo.

'Bibliografía sucinta: 1) Barros, C. (2009). Los libros de la cocina mexicana. México: Conaculta, p. 417. 2) De'Angeli, G. (2002). Cocina mexicana para el mundo. Saberes y sabores de Alicia Gironella De'Angeli. España: Everest, p. 351. 3) Iturriaga, J. (1998). Las cocinas de México / y II. México: FCE, pp. 69 y 77. 4) Juárez, J. (2008). Nacionalismo culinario. La cocina mexicana en el sig/o XX. Mexico: Conaculta, p. 359. 5) Kennedy, D. (2000). The Essential Cuisines of Mexico. USA: Clarkson Potter, p. 526. 6) Muñoz, R. (2000). Diccionario enciclopédico de gastronomía mexicana. México: Clío, p. 624. 7) Novo, S. (1967). Cocina mexicana. Historia gastronómica de la Ciudad de México. México: Porrúa, p. 361. 8) Pilcher, J. (2001). jVivan los tamales! La comida y la construcción de la identidad mexicana. México: Conaculta, p. 277. 
Dado que la República Mexicana y México comenzaron a existir oficialmente hasta la segunda mitad del siglo XIX, con la Constitución de 1857 y la supuesta definición de lo "nacional mexicano"; siempre ha sido un concepto más ideológico que sociocultural, un concepto que ha venido cambiando según la época y el gobierno en turno, sin ninguna continuidad objetiva.

De tal forma, hoy día la "cocina mexicana" se constituye como un conjunto de prácticas gastronómicas que son reguladas, ordenadas, desde un amplio discurso cada vez más institucional y académico. Hay una disciplina del saber y la praxis organizada desde universidades y escuelas de cocina, por comentaristas del ser de esta cocina, que analizan con sistema autores y textos, integrando o tratando de integrar un canon (o archivo principal) y su contexto; lo mismo que un discurso crítico y uno contracultural o de oposición.

La plataforma epistémica de dicho discurso la determina la voluntad de verdad científica e historiográfica, la separación (o intento) entre lo propio y lo impropio de la cocina mexicana; con nombres paradigma (por ejemplo, Cristina Barros y Dianne Kennedy) y textos emblemáticos (como el libro de Salvador Novo o los de José Luis Juárez López).

En este ensayo, el concepto "orden del discurso" es entendido a partir de la lección inaugural que dictó Michel Foucault en 1970 en el Collège de France, en la cátedra de "Historia de los sistemas de pensamiento". ${ }^{2}$ Allí se plantea que el "orden del discurso" busca comprender las tácticas y estrategias que utiliza el poder. Por tanto, la función crítica de este concepto consiste en enumerar todos los procedimientos utilizados para conjurar los poderes y peligros del discurso. El objetivo será la anunciación de la importancia del discurso en su dimensión de materialidad y de acontecimiento singular (Foucault, 2013).

Hoy día esta sociedad del discurso de la cocina mexicana cuenta con instituciones académicas como la carrera de gastronomía en la Universidad del Claustro de Sor Juana, las propuestas de la Escuela de Gastronomía Mexicana y las de Ambrosía Centro Culinario. Como también existe un Conservatorio de la Cultura Gastronómica Mexicana, Organismo Consultor de la Organización de las Naciones Unidas para la Educación, la Ciencia y la Cultura (Unesco).

La cocina mexicana es un orden del discurso que apenas ahora, en el siglo XXI, empieza a condensarse y tener sentido como concepto gastronómico. Aparecen ya, como se dijo, los textos canónicos ${ }^{3}$, tanto en los recetarios y libros de cocina, como en los escritos teóricos y de memorias, lo mismo que en los archivos y bibliotecas.

\footnotetext{
2 Foucault, M. (2013). El orden del discurso. México: Tusquets, pp. 64 y La arqueología del saber (1970), p. 355

${ }^{3}$ Cuatro (4) recetarios paradigma: 1) Anónimo. (1831). El cocinero mexicano o colección de las mejores recetas para guisar al estilo americano (3 tomos). México: Imprenta de Galván. 2) Anónimo. (1913). La cocinera poblana o el libro de las familias. México: Herrero Hermanos. 3) Anónimo. (2002). Formulario de la cocina mexicana. Puebla, siglo XIX. México: Conaculta. 4) Anónimo. (1888). Nuevo cocinero mexicano en forma de diccionario. París y México: Librería de Ch. Bouret.
} 
Además, estos textos básicos de la cocina mexicana tienen ya comentaristas especializados, académicos e independientes; los analizan con un sistema establecido y los ubican con rigor en el tiempo y el espacio de una gran tradición práctico-reflexiva. Esto permite organizar el gran cuerpo de la cocina mexicana dentro de diversas disciplinas y con distintas perspectivas, lo que permite reactualizar sus reglas de producción, transmisión y recepción.

Con ello se integra una nomenclatura, una regionalización; así como una antología de ingredientes, recetas, utensilios, técnicas y rituales de cocina. Los centros académicos institucionales y los grupos de especialistas forman las sociedades del discurso que lo generan, lo debaten y lo instituyen como válido o no válido. Lo anterior, hasta comenzar a consolidarse específicamente no solo como restaurantes y otros negocios de alimentos, sino como universidades, colegios y academias para pulir los conocimientos y fijarlos.

Se puede entender ahora que la cocina mexicana también, más que nada, es un lenguaje y, como ya se dijo, un orden del discurso. Es un gran archivo de palabras en forma de recetas y relatos; un modo de hablar y escribir sobre la preparación, presentación y consumo de alimentos. También la cocina mexicana es cosa de documentos y publicaciones; también forma parte de la sociocultura de las comidas y sus hábitos. Algo que desborda el cuadro de las recetas y las historias y anécdotas de cocineros y cocineras.

Para pensar mejor aquí en la cocina mexicana, y escribir una nota propia sobre ella, se hace una relectura de modo constante sobre el Libro de cocina de Dominga de Guzmán (1996). Este documento manuscrito constituye un texto fundamental, un punto de partida objetivo para la genealogía del proceso de construcción de la cocina mexicana; porque son platillos y técnicas del siglo XVIII.

Es la cocina del final del período barroco de la Nueva España; la cocina criolla que se reconoce y distingue también por "mexicana" y "americana". Una cocina diferente de la indígena, igual que de la mestiza y la hispana. En todo caso, como cocina ya se manifiesta como "mexicana", con personalidad y objetividad propias, comenzando lógicamente por el papel central de los chiles.

Lo primero que llama la atención para pensar en esta breve nota de la relectura es la muy precisa aparición de los diminutivos mexicanos en la redacción de casi todas las recetas de doña Dominga de Guzmán. Por ejemplo, para tomar una muestra, nada más en las primeras siete (7) recetas del libro existen estos diminutivos: "tantito", "cazuelita", "hartito", "aguadito", "tortita", "sequecita", "chilitos", "menuditos" y "menudita".

En ninguna de las primeras siete (7) recetas de doña Dominga falta el uso de un diminutivo. Cuando menos, y como se repiten una vez más "tortita" y "chilitos", en total son 11 diminutivos para las primeras siete (7) recetas. Diminutivos que, como bien se puede leer, son muy "mexicanos"; solo desde el interior del campo semántico de lo mexicano, en el habla se puede entender lo que estos sintagmas dicen. De otro modo, son deícticos oscuros. 
Solo las personas hablantes con plena competencia mexicana pueden tener una idea clara de qué tanto es "tantito" o "hartito". Ya que lo primero quiere decir "tanto como para que no falte" y lo segundo quiere decir "tanto como para que sobre un poco". Algo parecido vale para el significado de "aguadito" y "sequecito", donde el primer sintagma quiere decir "tanto como para que no esté por completo seco" y lo segundo es "tanto como para que no esté por completo aguado".

Donde no resulta tan claro el significado de la palabra es con el diminutivo "chilitos". ¿Qué tipo de chiles son en concreto estos "chilitos" de las recetas de la señora Guzmán? ¿Se les dice así por el tamaño o por la pungencia o "picor"? ¿O por la cantidad de los chiles? ¿Son pocos? ¿Verdes? ¿Secos? ¿Ahumados? No se puede saber con exactitud. Todo sentido literal en este caso concreto queda irresuelto. Pero muchas tradiciones y libros de cocina dejan sospechar que los "chilitos" son los chiles en vinagre.

Los diminutivos mexicanos son una transculturación probablemente de origen náhuatl, lengua en que los diminutivos son en realidad exaltaciones de lo nombrado. De tal forma, decir en náhuatl "señorcito" quiere decir en realidad "gran señor".

Alfonso Reyes hace una brillante reflexión sobre los diminutivos de la cocina mexicana en el Descanso XIII de sus Memorias de cocina y bodega (2002). El autor comienza planteando que esta tendencia "va de lo sublime a lo ramplón, manteniéndose generalmente en el nivel medio de la cortesía" (p. 516); cosa apreciable tanto en el habla popular como en la poesía superior de los mexicanos.

Él le encuentra su semilla "andaluza" a esta "cosquilla sensual" del diminutivo como "puntita de puñal" en México. No obstante, considera que la estructura determinante de su uso como identidad nacional proviene del Pacífico, de la Nao de Oriente y los "primores chinescos" que traía hasta el puerto de Acapulco. Con esto, de Reyes se identifica que este retintín mexicano de los chilitos, los frijolitos, el molito y sus tortillitas tiene entonces el tono refinado de la plata de Taxco y el barroco de Santa Prisca (Corcuera, 1996).

Por otra parte, ante la ambigüedad actual del significado de la palabra "tortita" o "torta", en el libro de Dominga de Guzmán se le emplea con el significado de pastel o pastelito dulce, un platillo de la repostería. Aunque ya entonces la receta en sí resulte ser la de un pastelito muy rústico, no poco barroco, para nuestros gustos actuales.

Entonces, para pensar en y desde las filosofías de la cocina mexicana, sí es importante no perder este uso de los diminutivos en la cocina. El empleo de diminutivos hasta el fastidio es un distintivo original de la gente de México en muchos sentidos. Aquí, en las cuestiones de la cocina mexicana, lo de los diminutivos es algo que conviene reflexionar desde varios puntos de vista, todos valiosos. 
Ya sea al pensar desde lo sociocultural abstracto del discurso de la cocina y los nombres de los platillos. Así sea al pensar desde lo muy concreto y significativo de las técnicas, las medidas y usos y costumbres de la cocina en sí de los alimentos.

Un "molito", por ejemplo, puede ser un gran mole de alta cocina; pero también puede ser una diminuta esferificación deconstructiva del mole poblano tradicional. Para que desde un tercer momento semántico se pueda entender por el término "molito" el plato fuerte de una fiesta importante, pública o privada. Todavía en un cuarto campo semántico más, esta palabra puede significar una ración grande o generosa de mole.

Con ello estamos pensando aquí en el carácter barroco de la cocina mexicana. Una cocina estructurada esencialmente como portada o retablo de templo novohispano; un mosaico geométrico con cuerpos y calles donde se presentan imágenes conceptistas sobre un tema. Una trama donde lo que se ve no es y lo que sí es no se ve; un tejido de ideas donde el ser y el no ser no se unen ni se separan, sino que se anudan con la conjunción " $y$ ".

Entonces, se trata de la cocina mexicana y el juego de los signos. Ni lógica ni absurdo, otro pensar, donde razón y sentimiento no son términos antitéticos ni dialécticos, sino emblemáticos. Según el deseo barroco, que ahora y aquí ya es ultrabarroco (Armstrong y Zamudio-Taylor, 2000), siempre subversivo, transgresor, pervertidor y divertido.

El sentido esencial de la cocina mexicana de que aquí se habla, escribe y piensa. De acuerdo con la episteme específica de la sociocultura mexicana y con el hecho de que somos lo que comemos. Porque primero está comer y luego está pensar; no se puede ser de otra manera.

\section{Referencias bibliográficas}

Armstrong, E. y Zamudio-Taylor, V. (eds.) (2000). Ultrabaroque. Aspects of Post-Latin American Art. San Diego, USA: Museum of Contemporary Art.

Corcuera, S. (1996). Entre gula y templanza. Un aspecto de la historia mexicana. México: FCE.

de Guzmán, D. y San Vicente, G. (1996). Recetario de doña Dominga de Guzmán, sig/o XVIII. Con una presentación de Guadalupe Pérez San Vicente. México: Conaculta y Sanborns Hermanos, p. 241.

Foucault, M. (2013). El orden del discurso. México: Tusquets.

Reyes, A. (2002). Obras completas, tomo XXV. México: FCE, pp. 217-516. 